\title{
Rapid tool based on a food environment typology framework for evaluating effects of the COVID-19 pandemic on food system resilience
}

\author{
Selena Ahmed ${ }^{1}(\mathbb{D}) \cdot$ Shauna M. Downs ${ }^{2} \cdot$ Chunyan Yang $^{3} \cdot$ Long Chunlin $^{4} \cdot$ Noah ten Broek ${ }^{5} \cdot$ Suparna Ghosh-Jerath $^{6}$
}

Received: 19 May 2020 / Accepted: 3 July 2020 / Published online: 16 July 2020

(C) International Society for Plant Pathology and Springer Nature B.V. 2020

\begin{abstract}
The coronavirus disease 2019 (COVID-19) and associated mitigation measures are highlighting resiliency and vulnerability of food systems with consequences for diets, food security, and health outcomes. Frameworks and tools are called for to evaluate impacts of the COVID-19 pandemic as well as identify entry points for implementing preparedness efforts. We support it is critical to adopt a food environment typology framework based on the different types of food environments that people have access to in order to examine how their relationship with food environments shift with disruptions such as COVID-19 and, ultimately impact diets and food security. Here, we provide an overview of applying a food environment typology framework for developing and implementing a rapid tool to evaluate the effects of COVID-19 on interactions people have with their food environments. This tool was developed on the basis of a preliminary case study with smallholder farmers in China that generated a set of key hypotheses. We modified the tool in order to be applicable to diverse contexts in low-, middle-, and high-income countries. Other researchers can implement the rapid tool presented here during times of COVID-19 as well as other disruptions towards identifying barriers and opportunities for enhancing food system resilience.
\end{abstract}

Keywords Food systems $\cdot$ Market food environments $\cdot$ Resilience $\cdot$ System disruption $\cdot$ Wild food environments

\section{Introduction}

The coronavirus disease 2019 (COVID-19) and associated mitigation measures are highlighting the resiliency and vulnerability of food systems with consequences for diets, food security, and health outcomes (Naja and Hamadeh 2020; Nat
Food 2020; IPES Food 2020). The COVID-19 pandemic has cross-cutting implications for all aspects of food systems from production, distribution, and storage to food environments, consumption, and waste, at all levels and scales (Zurayk 2020). On the production side of food systems, the COVID19 pandemic is disrupting farm management practices, access

Electronic supplementary material The online version of this article (https://doi.org/10.1007/s12571-020-01086-z) contains supplementary material, which is available to authorized users.

Shauna M. Downs

sd1081@sph.rutgers.edu

Selena Ahmed

selena.ahmed@montana.edu

Chunyan Yang

yangyahan@mail.kiz.ac.cn

Long Chunlin

long.chunlin@muc.edu.cn

Suparna Ghosh-Jerath

suparna.ghoshj@iiphd.org
Sustainable Food Systems Program, Department of Health and Human Development, Montana State University, Bozeman, MT 59717, USA

2 Department of Urban-Global Public Health, School of Public Health, Rutgers University, Newark, NJ 07102, USA

3 Kunming Institute of Zoology, Chinese Academy of Sciences, Kunming, Yunnan, China

4 Minzu University of China, Beijing, China

5 Livingston, MT, USA

6 Indian Institute of Public Health-Delhi, Delhi, India 
to on farm-input, labor schedules, food transport, and supply chains (Torero 2020). These supply chain disruptions are impacting consumer food environments, which coupled with COVID-19 mitigation measures such as lock-down, influence food access, dietary choices and food security. Moreover, the diets that we consume, and their impacts on our metabolic health and nutritional status, have important implications for the progression and pathology of COVID-19 (Muscogiuri et al. 2020).

In order to evaluate the impacts of COVID-19 on food systems as well as identify entry points for implementing mitigation and preparedness efforts, frameworks and tools are called for that allow for identification of food system resilience. Resilience is variably defined including as the ability of a system to absorb disturbance and retain the same structure and functions (Walker and Salt 2006). A food systems resilience approach addresses the complex relationships within food systems despite disturbances (Tendall et al. 2015; Ericksen et al. 2010; Ingram et al. 2010), such as climate change, the COVID-19 pandemic, as well as the interaction of these disturbances. Most approaches for examining the effects of a global crisis on food security have focused on specific stages in the food value chain (Tendall et al. 2015). We posit that critical to a food systems resilience approach for understanding the effects of COVID-19 and other disruptions is consideration of the food environment. More specifically, we support it is critical to adopt a food environment typology framework that examines shifts in people's interactions with different types of food environments.

Our working definition of the food environment is: "the consumer interface with the food system that encompasses the availability, affordability, convenience, quality and promotion, and sustainability of foods and beverages in wild, cultivated, and built (informal and formal) spaces that are influenced by the socio-cultural and political environment and ecosystems within which they are embedded" (Downs et al. 2020). The food environment is especially critical to focus on in the context of COVID-19 given that mitigation efforts have influenced consumers' ability to access and afford food, as well as its likely influence on convenience and food preferences. While the majority of food environment approaches focus on the formal built food environment, such approaches only partially explain the food environment in many low- and middle-income countries (Herforth and Ahmed 2015; Turner et al. 2017; Downs et al. 2020). Rather, we must adopt a food environment typology framework that is much more than the built food environment to examine the different types of food environments that individuals have access to in diverse contexts in low-, middle- and high-income countries and, how these shift in the face of COVID-19 and other disruptions.

In this article, we provide an overview of the food environment typology framework and its application for developing a rapid tool to evaluate the effects of COVID-19 on food environments. This tool was developed and implemented as a rapid pilot study with smallholder farmers in China at the onset of COVID-19 that generated a set of key hypotheses. We then modified the tool in order to increase its applicability to diverse contexts in low-, middle-, and high-income countries. Other researchers can implement the rapid tool presented here during times of COVID-19 as well as other disruptions, both acute and chronic shocks such as market failures and climate change, towards identifying barriers and opportunities for enhancing food system resilience.

Food environment typology framework The food environment typology framework comprises of two overarching types of food environments: natural and built environments (Downs et al. 2020; Fig. 1). These further comprise of wild, cultivated, informal market, and formal market food environments. Individuals have access to various types of food environments at a given time and this may shift over time, including over the long-term with development, periodically with different seasons, and due to acute disruptions, such as the COVID-19 pandemic and extreme weather events. It is important to evaluate the different types of food environments that people have access to, and how their relationship with these shift with time, in order to identify frailties and entry points for enhancing food system resilience.

\section{Rapid tool based on the Food environment typology frame- work for evaluating effects of COVID-19 on Food systems We} developed and implemented (after obtaining human subjects approval) a rapid tool based on the food environment typology framework at the onset of the COVID-19 pandemic (MarchApril 2020) with smallholder farmers $(n=60)$ and households living off-farm in rural and peri-urban contexts $(n=55)$ in Yunnan and Guizhou Provinces of China in communities where we have carried out long-term research. The rapid tool (Appendix 1) titled COVID-19 Surveillance Community Action Network (C-SCAN) for Food Systems includes a short set of interview questions that can be implemented as phone interviews, online surveys, or via mobile phone applications. Based on our initial interviews, we generated a set of hypotheses to refine the C-SCAN Food Systems tool. We further refined the tool through an iterative process of a panel of researchers working in diverse contexts in order for the CSCAN Food Systems tool to be suitable for implementation across different country contexts. The final C-SCAN Food Systems tool includes the following components: (1) underlying hypotheses, (2) sampling approach including time series sampling, (3) recommendations for adapting questions for local contexts, (4) interview script with consent and, (5) questionnaire. The questionnaire section is comprised of six parts including questions on demographics, food environments, diets, food preparation, income, and farming and gardening. 

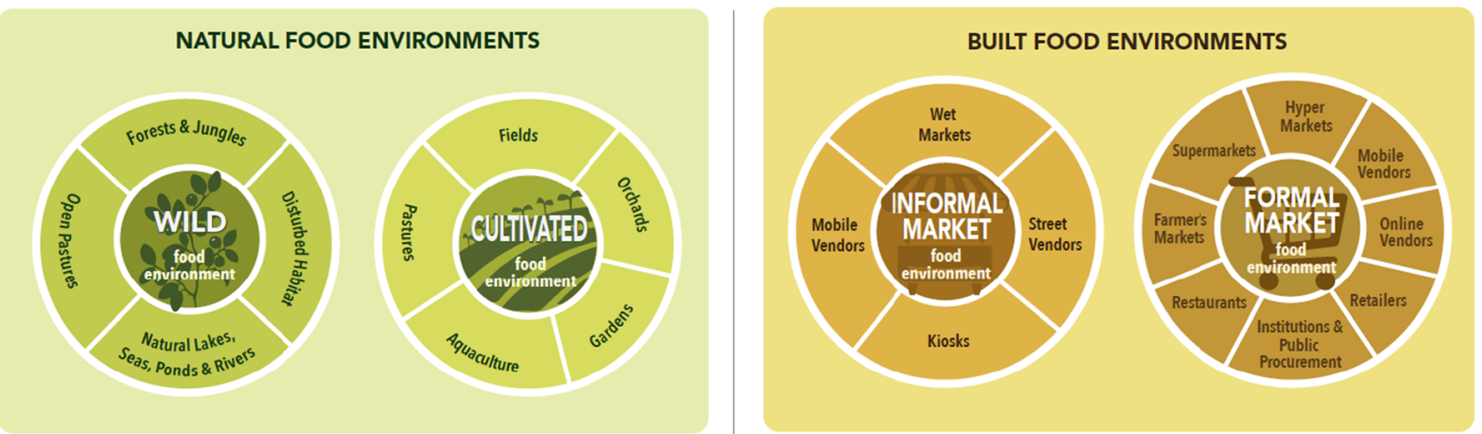

Fig. 1 Food environment typology. There are two overarching types of food environments comprising the food environment typology including natural and built environments. (reproduced from Downs et al. 2020)

Below, we share observations from our preliminary interviews in China as well as other emerging food environment evidence that informed the development of our hypotheses underlying the C-SCAN Food Systems tool.

Wild food environments Our preliminary C-SCAN Food Systems interviews in China indicate that in some cases, wild food procurement has increased with a shift in access away from built food environments. Although wild food environments are not a primary source of food acquisition, these environments are a source of nutrient-dense foods with diverse phytochemical profiles (Bharucha and Pretty 2010; Luo et al. 2019). While the food directly procured from wild food environments do not have financial costs, they do have costs in terms of acquisition and/or preparation time and occasionally financial cost of transport (Smith et al. 2019). Ninety-three percent of informants reported that their income has been impacted by the COVID-19 outbreak which has resulted in reduced purchasing power but more time for wild food procurement.

Cultivated food environments Our preliminary interviews in China indicate that households that rely primarily on cultivated food environments experienced less impacts to their diets compared to households primarily reliant on formal built food environments. The majority of households primarily reliant on cultivated food environments have not experienced changes in their diets with the pandemic. Over half the smallholders interviewed shared that their farming practices and schedules shifted with the pandemic. Of note, households that follow an agroecological approach in farming that focuses on minimum external input and mimicking a habitat that fosters ecosystem services through managing diversity at the genetic, species, and landscape levels are more resilient during the pandemic compared to households and communities with greater reliance on external input including purchased seeds, fertilizer, and pesticide. The importance of cultivated food environments is being recognized in high-income countries during times of COVID-19 as home cultivation and cooperative gardens increase to strengthen local food systems (Rao 2020).
Informal \& formal built food environments Our preliminary interviews in China suggest that COVID-19 disruptions to built food environments are affecting the availability, affordability, convenience, and quality of foods that people can access. In particular, those that are primarily reliant on formal built food environments, such as supermarkets that are dependent on global supply chains, are more vulnerable to dietary shifts compared to those that also access informal markets that rely on local procurement. For example, $73 \%$ of study informants shared that the affordability of foods in built (informal and formal) food environments decreased with the COVID-19 outbreak. On the positive side, new types of food environment innovations such as mobile phone food vendors and delivery services are emerging where formal built markets are failing to increase food access.

The vulnerabilities of built food environments are being elucidated during the COVID-19 pandemic and highlight our entrenched societal reliance on these environments (Nat Food 2020). The emergence of the SARS-CoV-2 virus that causes COVID-19 has been traced back to a wildlife market for food and medicine in China, bringing into question the food safety practices of wet markets (St. Cavish 2020). Amongst the most vulnerable sector of the food system during the pandemic is food service, which had seen a steady rise over the past five decades as people increasingly consumed food away from home. With lock-down measures, restaurants, fast food venues, and institution cafeterias temporarily closed, redirecting people to markets with more at-home meal preparation (IPES Food 2020).

Interactions with and between food environments Overall, $55 \%$ of the informants in our preliminary study shared that their relationship with the types of food environments they procure food has shifted with the COVID-19 outbreak. It is important to note that not only are people's reliance on food environments shifting, but that interactions between different types of food environments are also shifting. For example, food service closures are having chain reactions throughout the food system (Torero 2020). Farms that provide food to this 
sector are having difficulty selling their products and, in many cases, have dumped nutritious food due to distribution vulnerabilities (Torero 2020; Yaffe-Bellany and Corkery 2020; IPES Food 2020). While preparing meals at home is recognized to have nutritional benefits, it can be prohibitive in terms of costs for cooking equipment and supplies such as fuel as well as knowledge and skills for preparing healthy meals.

On the basis of our preliminary research with smallholder communities in China, we propose the following hypotheses based on the food environment typology framework for exploring effects of COVID-19 on food systems towards elucidating entry points for designing programs and policies for supporting resilience.

(1) The greater the number and the more diverse the types of food environments that individuals, households, and communities have access to, the greater their resilience with regard to diets and food security. This hypothesis of increased diversity of food environment types is directly aligned with resilience theory where diversity is a key socio-ecological determinant of resilience (Walker and Salt 2012).

(2) In times of the COVID-19 pandemic, wild foods will serve an increased role in supporting food security and people will have more time to procure wild foods.

(3) Traditional ecological knowledge and reliance on wild food environments enhances food security and food system resilience.

(4) Procuring food from cultivated food environments during times of COVID-19 will enhance food security and food system resilience.

(5) Cultivating food following an agroecological approach that fosters ecosystem services through managing genetic, species, and landscape diversity will be more resilient during the COVID-19 pandemic compared to households and communities with greater reliance on external input.

(6) Informal built food environments that rely on local agricultural products will be more resilient during the COVID-19 pandemic compared to formal built food environments that are dependent on lengthy global supply chains.

The C-SCAN Food Systems tool presented here (Appendix 1) is designed to address these hypotheses in a rapid manner in diverse contexts in low-, middle-, and high-income countries. While the tool provides a snapshot of how consumers interface with different types of food environments in the face of food system disruptions, it can be combined with additional methods and tools to gain further insight into the resiliency of those systems. Moreover, the questions are designed to elicit yes/no responses in order to enable a rapid assessment, but if time permits the responses can be elaborated on in greater detail.

We encourage other researchers to adopt the C-SCAN Food Systems tool for the community contexts where they live and work. The use of a common tool will enable us as a global community of food security researchers to share lessons, identify patterns as well as context specific factors that inform the development of evidence-based plans for transforming the food system to one that is more resilient to future disruptions.

Authors' contributions (optional: please review the submission guidelines from the journal whether statements are mandatory) SA and SMD designed the food environment typology framework; All authors contributed to the design of the survey tool and the writing of this manuscript.

Funding information Funding (information that explains whether and by whom the research was supported) Support was provided by NSF RII Track-2 FEC OIA 1632810, Montana INBRE (NIH NIGMS 5P20GM103474-20), and CAIRHE (NIH NIGMS P20GM104417)).

\section{Compliance with ethical standards}

Conflicts of interest/competing interests (include appropriate disclosures) Not applicable.

Ethics approval (include appropriate approvals or waivers) Ethics approval was received by Minzu University of China and Montana State University.

Consent to participate (include appropriate statements) All participants provided prior informed consent to participate in this study.

Consent for publication (include appropriate statements) All authors provide consent for publication.

\section{References}

Bharucha, Z., \& Pretty, J. (2010). The roles and values of wild foods in agricultural systems. Philosophical Transactions of the Royal Society B, 365(1554), 2913-2926. https://doi.org/10.1098/rstb. 2010.0123 .

Downs, S., Ahmed, S., Fanzo, J., \& Herforth, A. (2020). Food environment typology: Advancing an expanded definition, framework, and methodological approach for improved characterization of wild, cultivated, and built food environments toward sustainable diets. Foods, 9, 532. https://doi.org/10.3390/foods9040532.

Ericksen, P. J., Bohle, H.-G., \& Stewart, B. (2010). Vulnerability and resilience of food systems. Food Security and Global Environmental Change. London: Earthscan.

Herforth, A., \& Ahmed, S. (2015). The food environment, its effects on dietary consumption, and potential for measurement within agriculture-nutrition interventions. Food Security, 7, 505-520.

Ingram, J. S. I., Ericksen, P. J., \& Liverman, D. (Eds.). (2010). Food security and global environmental change. London: Earthscan.

iPES Food. (2020) COVID-19 and the crisis in food systems: Symptoms, causes, and potential solutions. iPES http://www.ipes-food.org/ img/upload/files/COVID-19_CommuniqueEN.pdf. 
Luo, B., Li, F., Ahmed, S., \& Long, C. (2019). Diversity and use of medicinal plants for soup making in traditional diets of the Hakka in West Fujian Province, China. Journal of Ethnobiology and Ethnomedicine, 15(1), 60. https://doi.org/10.1186/s13002-019-0335-y.

Muscogiuri, G., Barrea, L., Savastano, S., \& Colao, A. (2020). Nutritional recommendations for CoVID-19 quarantine. European Journal of Clinical Nutrition, 74, 850-851. https://doi.org/10.1038/s41430020-0635-2.

Naja, F., \& Hamadeh, R. (2020). Nutrition amid the COVID-19 pandemic: A multi-level framework for action. European Journal of Clinical Nutrition. https://doi.org/10.1038/s41430-020-0634-3.

Nat Food. (2020). Food system stress-test. Nature Food, 1(186). https:// doi.org/10.1038/s43016-020-0071-4.

Rao, T. (2020) Food supply anxiety brings back victory gardens. New York Times. https://www.nytimes.com/2020/03/25/dining/victorygardens-coronavirus.html

Smith, E., Ahmed, S., Byker Shanks, C., Dupuis, V., Running Crane, M., Eggers, M., Pierre, M., Flagg, K. (2019). Contribution of wild foods to food security and cultural values on the Flathead reservation of the Confederated Salish \& Kootenai Tribes in the context of climate change. Journal of Agriculture, Food Systems, and Community Development. https://doi.org/10.5304/jafscd.2019.09B.011.

St. Cavish, C. (2020) No, China's fresh food markets did not cause coronavirus. Los Angeles Times. https://www.latimes.com/food/story/ 2020-03-11/coronavirus-china-wet-markets

Tendall, D. M., Joerin, J., Kopainsky, B., Edwards, P., Shreck, A., Le, Q. B., Krütli, P., Grant, M. \& Six, J. (2015). Food system resilience: defining the concept. Global Food Security, 6, pp. 17-23.

Torero, M. (2020). Without food, there can be no exit from the pandemic: Countries must join forces to avert a global food crisis from COVID-19. Nature, 580, 588-589. https://doi.org/10.1038/d41586-020-01181-3.

Turner, C., Kadiyala, S., Aggarwal, A., Coates, J., Drewnowski, A., Hawkes, C., Herforth, A., Kalamatianou, S., Walls, H. (2017) Concepts and Methods for Food Environment Research in Low and Middle Income Countries; innovative methods and metrics for agriculture and nutrition actions (IMMANA) Programme: London.

Walker, B.,\& Salt, D. (2006). Resilience thinking: sustaining ecosystems and people in a changing world, Island Press.

Walker, B., \& Salt, D. (2012). Resilience thinking: sustaining ecosystems and people in a changing world. Island Press.

Yaffe-Bellany, D., Corkery, M. (2020) Dumped milk, smashed eggs, plowed vegetables: Food waste of the pandemic. The New York Times. https://www.nytimes.com/2020/04/11/business/ coronavirus-destroying-food.html

Zurayk, R. (2020). Pandemic and Food security. Journal of Agriculture, Food Systems, and Community Development, 9(3), 1-5.

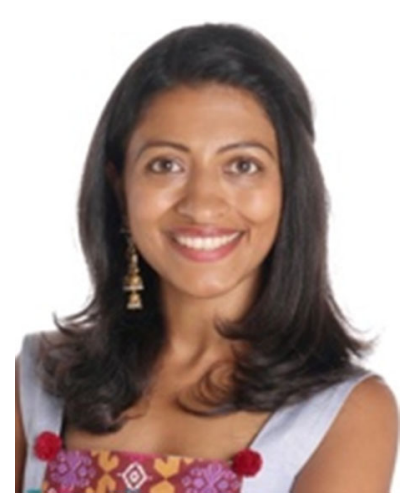

Selena Ahmed is an Associate Professor of Sustainable Food Systems at Montana State University and Director of the Translational Biomarkers Core of the Center for American Indian and Rural Health Equity.

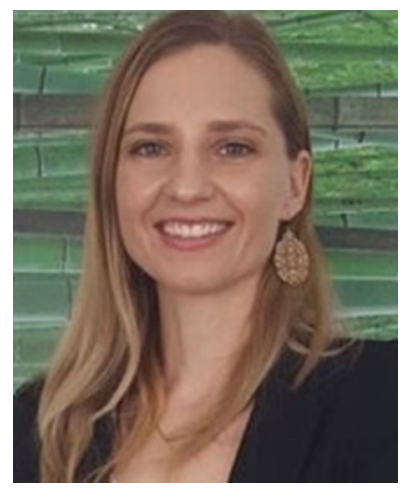

Shauna M Downs is an Assistant Professor in the Department of Urban-Global Public Health, School of Public Health at Rutgers University.

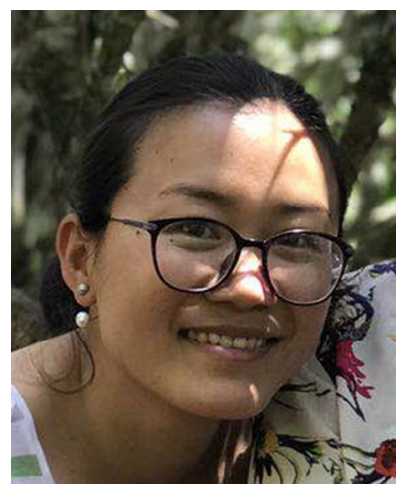

Chunyan Yang a Scientist at Kunming Institute of Zoology of the Chinese Academy of Sciences.

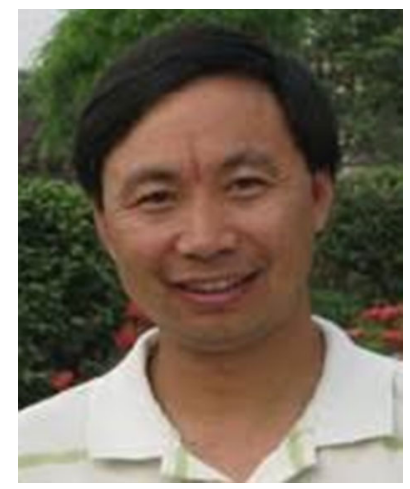

Long Chunlin is a Professor II at the College of Life and Environmental Sciences, Minzu University of China. Chunlin does researches in Ethnobotany, Ethnoecology, Ethnopharmacology, Plant Genetic Resources, Phytochemistry, Plant Taxonomy, and Biodiversity. 


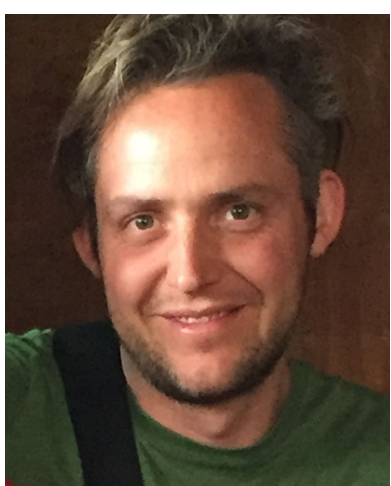

Noah ten Broek is a chef, food and beverage consultant, and independent contractor.

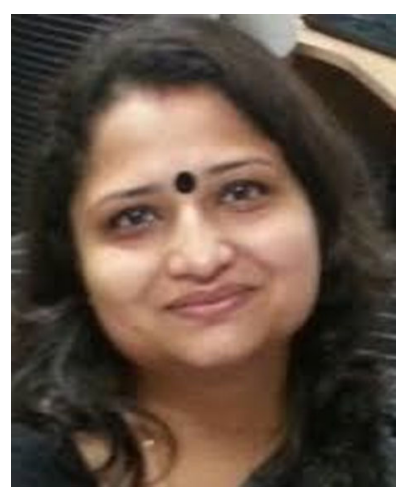

Suparna Ghosh-Jerath is a

Professor at the Indian Institute of Public Health. 